\title{
TEORIJA KONEKTIVIZMA U OBRAZOVANJU ${ }^{2}$
}

Apstrakt. Sve veće prodiranje tehnologije u proces obrazovanja rezultiralo je aktuelizovanjem sintagme o pedagogiji usmerenoj ka tehnologiji u okviru promišljanja o učenju za digitalno doba. U tom kontekstu, cilj rada jeste da se analizira konektivizam koji se definiše kao teorija učenja za digitalno doba u okviru onlajn učenja. Ovaj cilj konkretizovan je na sledeće zadatke: predstavljenje i analiziranje osnovnih postavki konektivizma kao potencijalne nove teorije učenja i dovođenje $\mathrm{u}$ vezu tih postavki $\mathrm{s}$ idejema učenja Ivana Iliča $\mathrm{u}$ okviru teorija deškolovanja, istraživanje relacija između konektivizma i drugih teorija učenja (biheviorizam, kognitivizam i konstruktivizam) i razmatranje kritika upućenih konektivizmu. Na osnovu analizirane literature izvode se zaključci o mogućnostima primene i aktuelizovanja teorije konektivizma u obrazovanju.

Ključne reči: konektivizam, konstruktivizam, onlajn učenje, teorije deškolovanja

\section{UVOD}

Sve veće prodiranje tehnologije u proces obrazovanja rezultiralo je aktuelizovanjem sintagme o pedagogiji usmerenoj ka tehnologiji (Chetty, 2013), odnosno aktuelizovanjem konektivizma kao teorije učenja za digitalno doba u okviru onlajn učenja. Idejni tvorac teorije konektivizma je Džordž Simens (George Siemens) koji je tokom 2004. godine predstavio konektivizam na svom blogu, da bi ga u 2005. godini, nakon pristiglih

\footnotetext{
${ }^{1}$ Maja Bosanac, bosanac.maja@ff.uns.ac.rs

${ }^{2} \mathrm{Rad}$ je nastao kao rezultat rada na projektu koji se realizuje na Filozofskom fakultetu Univerziteta u Novom Sadu a koji finansira Ministarstvo prosvete, nauke i tehnološkog razvoja RS na osnovu Ugovora o realizaciji i finansiranju naučnoistraživačkog rada NIO u 2021. godini.
} 
povratnih informacija od strane akademskih radnika, revidirao (Utecht \& Keller, 2019). Dauns (Downes, 2019) ističe da je na konferenciji pod nazivom Konektivizam i „povezano znanje“ (Connectivism and Connective Knowledge) održanoj 2007. godine početnu formulaciju konektivizma sledila diskusija i njeno unapređivanje. Nakon toga, Simens (Siemens, 2012) određuje konektivizam kao novu teoriju učenja u okviru distribuiranih mreža i socijalnog učenja.

Kao cilj ovog rada postavlja se analiza konektivizma koji se definiše kao teorija učenja za digitalno doba u okviru onlajn učenja kako bi se ta teorija dovela u vezu s pedagogijom. Ovaj cilj konkretizovan je kroz sledeće zadatke: predstavljanje i analiziranje osnovnih postavki konektivizma kao potencijalne nove teorije učenja, dovođenje u vezu tih postavki s idejema učenja Ivana Iliča u okviru teorija deškolovanja, potom istraživanje relacija između konektivizma i drugih teorija učenja (biheviorizam, kognitivizam i konstruktivizam) i na kraju razmatranje kritika upućenih konektivizmu. Analiziranje literature omogući će da se izvedu zaključci o mogućnostima primene i o aktuelizovanju konektivizma u obrazovanju.

\section{KARAKTERISTIKE KONEKTIVIZMA}

Prema definiciji datoj u Rečniku stranih reči i izraza (Klajn i Šipka, 2012), reč konekcija (engl. connection) označava vezu koja omogućava razmenu informacija. Pojmovnim određenjem dobija se uvid u značaj konektivizma za učenje koje, umesto povezivanja s informacijama, ukazuje na značaj povezivanja s izvorima informacija i preispitivanja postojećeg znanja. Upravo u tom okviru pojedini autori (Barnett, McPherson \& Sandieson, 2013) ističu značaj konektivizma za pedagogiju, a on se odnosi 
na razvoj bogatih i moćnih veza kojima se pristupa brzo i lako. U procesu učenja samo pamćenje informacija više nije od tolikog značaja; učenje se tiče prepoznavanja veza koje menjaju mrežu, istovremeno dodajući nove veze, potencijalno bez prisustva nastavnika.

Pozivajući se na ideje Stivensona (Karen Stephenson), Simens (Siemens, 2005) naglašava kako je iskustvo dugo smatrano za najboljeg nastavnika. Međutim, s obzirom na to da nije moguće sve doživeti putem ličnog iskustva, iskustva drugih ljudi postaju surogat znanja. Prema mišljenu Simensa (Siemens, 2005), konektivizam, kao teorija koja proučava načine na koji ljudi usvajaju znanje u digitalnoj eri, predstavlja integraciju ideja koje se javljaju u teorijihaosa, u samoorganizovanju i u mrežama. Za razliku od konstruktivizma koji ističe da se kod onih koji uče podstiče razumevanje kroz smislene zadatke, teorija haosa navodi na to da značenje postoji i da je izazov za one koje uče da prepoznaju obrasce koji se čine skrivenim. Otuda su stvaranje značenja i formiranje veza između specijalizovanih zajednica veoma važne aktivnosti u procesu učenja. Značajno za teoriju haosa jeste to da prepoznaje povezanost svega sa svime i zato se razvoj sposobnosti identifikovanja promena i prilagođavanja izmenjenim obrascima postavlja kao ključni zadatak učenja. U okviru objašnjenja konektivističke teorije kao primer se navodi 'efekat leptira' (Butterfly Effect) koji opisuje kako male varijacije u početnim uslovima mogu da rezultiraju radikalno različitim ishodima. Ova analogija može da se primeni i u oblasti obrazovanja; ukoliko se promene osnovni uslovi, sama odluka neće biti u istoj meri valjana kao što je bila u vreme kada je doneta prvi put. Samoorganizovanje može da se definiše kao spontano formiranje dobro organizovanih struktura, obrazaca ili ponašanja iz slučajnih početnih uslova (Rocha, 1998, prema: 
Siemens, 2005). Učenje kao proces samoorganizacijezahteva da sistem lični ili sistem učenja na organizacionom nivou - bude informativno otvoren. Kako bi mogao da upravlja sopstvenim interakcijama s okolinom, sistem mora da bude u stanju da promeni svoju strukturu. Mrežu predstavljaju skupovi odnosa između entiteta; računarske mreže, električne mreže ili društvene mreže. Ona funkcioniše po jednostavnom principu tako što se ljudi, grupe, sistemi, čvorovi ili entiteti mogu povezivati kako bi se kreirala integrisana celina. Promene unutar mreže imaju talasne efekte na celinu, a entiteti koji steknu snažniju povezanost uspešniji su u sticanju dodatnih veza. Primenjene na obrazovanje, te ideje znače da zajednice koje se specijalizuju i koje dobijaju priznanje za stručnost imaju veće šanse da budu identifikovane, što rezultira „unakrsnim oprašivanjem“ zajednica učenja (Siemens, 2005). Ciklus razvoja znanja (od pojedinca ka mreži, ka organizaciji) omogućava onima koji uče da ostanu u toku u svom polju zahvaljujući već formiranim vezama.

Iako konektivizam u oblasti obrazovanja predstavlja novinu, začeci te teorije i umreženog učenja pojavili su se tokom sedamdesetih godina 20. veka kada je Ivan Ilič (Ivan Illich) predstavio svoje ideje o deškolovanju društva i podstakao pokret za učenje u društvenom okruženju usmerenog na onoga koji uči (Sahin, 2012). Ilič (1980), najpoznatiji radikalni zastupnik teorije deškolovanja, odbija obavezno državno školovanje kao mehanizam društvene reprodukcije, te predlaže ukidanje formalnih institucija obrazovanja i njihovu zamenu sa sledećim mrežama:

1. Službe za upućivanje na obrazovne predmete. Te službe namenjene su olakšavanju pristupa obrazovnim objektima (bibliotekama, muzejima, pozorištima, fabrikama, poljoprivrednim dobarima) koji 
se koriste u formalnom obrazovanju. Osnovna pretpostavka za ovu mrežu učenja predstavlja činjenica da stvari pružaju osnovne mogućnosti za učenje. Od kvaliteta sredine i povezanosti pojedinca s njom zavisi i obim njegovog učenja.

2. Berze veština. Za razliku od službi koje su usmerene na stvari koje mogu da budu društvena svojina, nastavnici veština jesu lica spremna da prenose svoju veštinu na one koji su spremni da njome ovladaju. Razmena veština omogućava ljudima da iskažu ono u čemu su vični, odnosno da iskažu pod kojim uslovima su spremni da služe kao uzor licima zainteresovanim za ovladavanje određenom veštinom.

3. Združivanje parnjaka. Reč je o komunikacionoj mreži namenjenoj pojedincima koji žele da opišu područje u okviru kojeg žele da se obrazuju i pronađu partnera $s$ istim ili sličnim interesima. U ovoj mreži ističe se značaj spajanja osoba sa zajedničkim interesima, za razliku od berze veština gde pojedinci prenose svoju veštinu na one koji njome još nisu ovladali.

4. Službe za upućivanje na prosvetne radnike. Ovu službučine profesionalci, paraprofesionalci i slobodnjaci čija imena mogu da budu uvrštena u imenik, gde se, pored njihovih adresa i samoopisa, navode i uslovi pod kojima su njihove usluge dostupne. Takvi prosvetni radnici, kako navodi Ilič, mogli bi se odabrati na osnovu anketiranja ili konsultovanja njihovih ranijih polaznika.

Jednu od prednosti ovih obrazovnih mreža, prema mišljenju Iliča, predstavlja činjenica da planiranje časova i administrativni poslovi, koji inače oduzimaju mnogo vremena, ne bi bili zastupljeni u radu mreža. Iličeve 
mreže učenja zapravo onima koji uče predstavljaju različite prilaze koji otvaraju pristup obrazovnim mogućnostima za određivanje i postizanje vlastitih ciljeva. U literaturi se naglašavaju paralele između savremenih onlajn mreža i Iličeve obrazovne vizije, posebno njegove ideje o „mrežama zajednice“ (Kop \& Hill, 2008). Onlajn mreže, takođe, okupljaju zainteresovane grupe autonomnih učesnika, dok je Ilič svoje mreže ili obrazovne resurse zamišljao na lokalnom nivou i analizirao ih u kontekstu tehnologija sedamdesetih godina 20. veka. Onlajn mreže mogu biti otvorene i mogu podsticati veze s raznovrsnim učesnicima koji u razmene unose svoje ideje i svoj 'bekgraund'. Takve okolnosti mogu podsticati raspravu, ali bi lokalne zajednice i njihov razvoj bili od manjeg značaja u odnosu na dominantnu kulturu na mreži.

Važno je reći da konektivizam zastupa takvu organizaciju učenja $u$ kojoj ne postoji suma znanja koja bi trebalo da se prenese sa nastavnika na učenika i u kojoj se učenje ne odvija na jednom mestu. Umesto toga, znanje se distribuira putem mreže i angažovanje ljudi na mreži predstavlja učenje. Tako se u literaturi (Kop, 2011) ističe da konektivizam predviđa mogućnost unapređivanja učenja kroz četiri glavne vrste aktivnosti: (1) agregaciju pristup i prikupljanje širokog spektra resursa za čitanje, gledanje ili igru, (2) uspostavljenje odnosa - nakon čitanja, gledanja ili slušanja sledi promišljenje i povezivanje sadržaja učenja s onim što se već zna ili sa ranijim iskustvom; (3) kreiranje - nakon refleksije i procesa stvaranja značenja, oni koji uče mogu sami nešto kreirati (na primer, blog); (4) deljenje - oni koji uče mogu deliti na mreži artefakta kroz interakciju s drugima. 
U literaturi se danas ističe nekoliko principa konektivizma (Siemens, 2005). Principu da se učenje i znanje zasnivaju na raznovrsnosti mišljenja pristupa se u okviru novih mogućnosti koje nudi internet, a to je posebno mogućnost upotrebe Vikipedije (Utecht \& Keller, 2019). Pri tome se ukazuje na moć učenja i znanja koje je oblikovano različitim mišljenjima, a u slučaju Vikipedije brojni korisnici proveravaju jedni druge. Pojedini autori (Murley, 2008, prema: Utecht \& Keller, 2019) ukazuju na potrebu da se učenici uče kako da pravilno koriste i procenjuju digitalne resure, umesto da se odvraćaju od njih. Principom da je učenje proces povezivanja sa specijalizovanim čvorovima ili izvorima informacija ukazuje se na značaj dostupnih i otvorenih podataka za nova otkrića. Sledeći princip konektivizma podvlači da izvori učenja mogu da leže u samim uređajima (tvorevinama koje nisu ljudske); računari, kao uređaji, uče od svojih korisnika za svoje korisnike, a učenje kako se koriste te informacije za kreiranje novih rezultata može da osnaži i nastavnike i učenike. Sledeći princip konektivizma odnosi se na to da je kapacitet saznavanja važniji od onoga što se trenutno zna. Ovaj princip je od posebnog značaja u periodu eksplozije informacija kada je bitno razviti sposobnost pronalaženja relevantnih informacija i njihovog kritičkog razmatranja (Utecht \& Keller, 2019). Princip koji naglašava da je negovanje i održavanje veza potrebno da bi se omogućilo kontinuirano učenje ukazuje na to da postoji nova era saradnje, pri čemu se saradnja ne dešava sama po sebi već je nju potrebno kreirati, održavati i negovati (na primer LinkedIn-a). Sledeći princip odnosi se na shvatanje da sposobnost da se uoče veze između polja, ideja i koncepata predstavlja bazičnu veštinu (Siemens, 2005). Takva sposobnost omogućava kreiranje novog znanja, a sami učenici u tom procesu postaju 
aktivni proizvođači znanja. Zato je u današnjem umreženom društvu važno oblikovanje situacija učenja u kojima se od učenika zahteva da traže veze između ideja i koncepata, a zatim i da kreiraju nova značenja iz tih veza (Utecht \& Keller, 2019). Sledeći princip sugeriše da je tačno i ažurirano znanje svrha svih aktivnosti učenja; u svetu u kojem velikom brzinom nastaju nove informacije, učenje kako da se pronađu ažurirane informacije i njihovo kritičko promišljanje jesu ključne aktivnosti. Naredni princip konektivizma ukazuje da donošenje odluka samo po sebi predstavlja proces učenja, pri čemu se izbor onoga što se uči i značenja dolazećih informacija sagledavaju kroz objektiv promenjive stvarnosti.

\section{KONTEKTIVIZAM KAO NOVA TEORIJA UČENJA}

Tri dobro poznate teorije učenja - biheviorizam, kognitivizam i konstruktivizam - danas se u literaturi posmatraju kao teorije učenja za predigitalno doba (Barnett et al., 2013). Ukazuje se na manjkavosti ovih teorija učenja za digitalno doba, i u tom se kontekstu konektivizam predlaže kao nova teorija učenja zasnovana na interakciji između umreženih članova (Tabela 1). Ključna obeležja biheviorizma, kognitivizma i konstruktivizma ukazuju na njihove međusobne značajne razlike, dok $\mathrm{u}$ isto vreme ta obeležja imaju dodirnih tačaka sa konektivizmom. Posebno, ukoliko se o konektivizmu razmišlja u obrazovnom okviru, on uključuje mnoga shvatanja tri poznate teorije učenja. Tako, na primer, aspekt biheviorizma $u$ konektivizmu čini zahtev koji se odnosi na to da je uslov da se nešto sazna, sposobnost da se nešto učini. Konektivizam s kognitivizmom deli pojmove o neuronskim mrežama, dok se istovremeno zasniva na idejama situacione 
kognicije i društvene zajednice koje se susreću u socijalnom konstruktivizmu (Slavich \& Zimbardo, 2012, prema: Barnett et al, 2013).

Tabela 1. Komparacija četiri pristupa učenju (Ireland, 2007, prema: Barnett et al., 2013: 687)

\begin{tabular}{|c|c|c|c|c|c|}
\hline & Pitanja & Biheviorizam & Kognitivizam & Konstruktivizam & Konektivizam \\
\hline 1. & $\begin{array}{l}\text { Kako se } \\
\text { odvija } \\
\text { učenje? }\end{array}$ & $\begin{array}{l}\text { „crna kutija“ - u } \\
\text { fokusu je } \\
\text { opažljivo } \\
\text { ponašanje }\end{array}$ & strukturisano & $\begin{array}{l}\text { socijalno kreiranje } \\
\text { značenja }\end{array}$ & $\begin{array}{l}\text { distribuirano } \\
\text { unutar mreže, } \\
\text { društveno, } \\
\text { tehnološki } \\
\text { potpomognuto, } \\
\text { identifikovanje i } \\
\text { interpretiranje } \\
\text { obrazaca }\end{array}$ \\
\hline 2. & $\begin{array}{l}\text { Koji faktori } \\
\text { utiču na } \\
\text { učenje? }\end{array}$ & $\begin{array}{l}\text { nagrada, kazna, } \\
\text { spoljašnji } \\
\text { stimulusi }\end{array}$ & $\begin{array}{l}\text { postojeće } \\
\text { sheme, } \\
\text { prethodno } \\
\text { iskustvo }\end{array}$ & $\begin{array}{l}\text { uključenost, } \\
\text { participacija, } \\
\text { društveni, kulturni }\end{array}$ & $\begin{array}{l}\text { raznovrsnost } \\
\text { mreža }\end{array}$ \\
\hline 3. & $\begin{array}{l}\text { Koja je } \\
\text { uloga } \\
\text { pamćenja? }\end{array}$ & $\begin{array}{l}\text { pamćenje se } \\
\text { zasniva na } \\
\text { ponovljenim } \\
\text { iskustvima - } \\
\text { nagrada i kazna } \\
\text { su od najvećeg } \\
\text { uticaja }\end{array}$ & $\begin{array}{l}\text { kodiranje, } \\
\text { skladištenje }\end{array}$ & $\begin{array}{l}\text { prethodno znanje } \\
\text { smešteno u } \\
\text { trenutni kontekst }\end{array}$ & $\begin{array}{l}\text { adaptivni obrasci, } \\
\text { reprezentacije } \\
\text { trenutnog stanja }\end{array}$ \\
\hline 4. & $\begin{array}{l}\text { Kako se } \\
\text { odvija } \\
\text { transfer? }\end{array}$ & $\begin{array}{l}\text { stimulus, } \\
\text { odgovor }\end{array}$ & $\begin{array}{l}\text { umnožavanje } \\
\text { konstrukcija } \\
\text { znanja onog } \\
\text { koji saznaje }\end{array}$ & socijalizacija & $\begin{array}{l}\text { povezivanje } \\
\text { čvorova }\end{array}$ \\
\hline 5 . & $\begin{array}{l}\text { Vrste } \\
\text { učenja koje } \\
\text { teorija } \\
\text { najbolje } \\
\text { opisuje? }\end{array}$ & $\begin{array}{l}\text { učenje } \\
\text { zasnovano na } \\
\text { zadacima }\end{array}$ & $\begin{array}{l}\text { rasuđivanje, } \\
\text { jasni ciljevi, } \\
\text { rešavanje } \\
\text { problema }\end{array}$ & društveno & $\begin{array}{l}\text { kompleksno } \\
\text { učenje, brzo } \\
\text { menjanje suštine, } \\
\text { različiti izvori } \\
\text { znanja }\end{array}$ \\
\hline
\end{tabular}

Kada je reč o okruženju s povećanim pristupom tehnološkim alatima, značajno je ukazati na to da oni koji uče sa sposobnošću da samousmeravaju svoje učenje, da pronalaze informacije iz raznovrsnih izvora ne deluju najbolje u biheviorističkim i kognitivnističkim okvirima. Uz to, njihovo učenje se više odnosi na integraciju i kritičke analize nego na 
jednostavno stvaranje značenja (Barnett et al., 2013). Smeštajući grupu onih koji uče i njihove veze u centar obrazovnog procesa, konektivizam kao teorija učenja drugačije sagledava proces učenja i donosi nove mogućnosti za kolaborativno učenje, upotrebu različitih izvora informacija, više prilika za razvoj autonomije u učenju, dodatne mogućnosti za samostalno učenje, kao i za samostalno odlučivanje i učenje kroz deljenje i razmenu znanja (Pavlović i Petrović, 2019). Značajno je ukazati i na uticaj i upotrebu konektivizma kao epistemološke osnove masovnih otvorenih onlajn kurseva (Bali, 2014). Za razliku od tradicionalnih masovnih otvorenih onlajn kurseva koji su prema načelima biheviorizma, kognitivizma i ponekad konstruktivizma, konektivistički pristup masovnim otvorenim onlajn kursevima smatra se za poslednju generaciju pedagogije učenja na daljinu u okviru koje se široko koriste društveni mediji, a učenje odnosi na sposobnost konstruisanja i kretanja kroz mreže.

\section{OGRANIČENJA KONEKTIVIZMA}

Iako konektivizam predstavlja novinu u obrazovanju, na njegov uticaj ukazuje tendencija da se uz tri dobro poznata „izma“ - biheviorizam, kognitivizam i kostruktivizam - dodaje i konektivizam (Calvani, 2008). Međutim, pojedini autori (Norris, 2001, prema: Kop \& Hill, 2008) iskazuju zabrinutost zbog mogućnosti nedostatka kritičnog angažovanja u okviru onlajn učenja, zbog iskušenja da se povezuju pojedinci s istomišljenicima umesto da budu angažovani u izazovnijim razmenama sa stručnjacima kao što su, na primer nastavnici u učionicama. Dodatno, ukazuje se i na to da je leva strana mozga logična, usmerena na obradu činjenica, analitička, kvantitativna i verbalna, a da desna strana mozga - holistička, zadužena za 
emocije, intuiciju i neverbalne procese - postaje ugrožena u digitalnoj eri (Votson, 2016). Reč je o tome da je leva strana mozga dobra za brzo donošenje odluka i usmerena na deliće informacija pa su iz tih razloga ove aktivnosti podsticane u okviru digitalne tehnologije. Suprotno, desna strana mozga koja daje širu sliku i koja je usmerena na duboko razmišljanje postaje zanemarena u okviru upotrebe digitalne tehnologije.

Značajna kritika konektivizma može se pronaći i u okviru kritičke pedagogije. $\mathrm{U}$ okviru freireanske pedagogije, nastavnik ulazi s učenicima $\mathrm{u}$ dijalog, koji je čin saznavanja i zajedničkog postizanja razumevanja stvarnosti (Freire, 2002), radije nego što pokreće razmenu ideja koja bi ostala na nivou „proživljenog iskustva pojedinca“ (Kop \& Hill, 2008). Dakle, susret nastavnika i učenika koji postavljaju pitanja o čemu će voditi dijalog, pretpostavlja identifikovanje socijalnog, a ne samo individualnog karaktera saznavanja. Ističe se i da se sposobnost kritičkog angažovanja neće razvijati ukoliko se uloga nastavnika svede isključivo na „facilitatora“, što predstavlja ulogu tutora široko prihvaćenu u e-učenju (Salmon, 2004, prema: Kop \& Hill, 2008). Štaviše, u konektivističkom onlajn okruženju učenja, s naglaskom na informalno učenje i izbor pojedinca da stupi $u$ kontakt sa stručnjacima izvan učionice, kritički pristup i lokalni konteksti mogli bi biti potpuno zapostavljeni. Nedostatak kritičkog angažovanja tutora - uz opadajući nivo kontrole od strane institucije - prepostavlja visok nivo autonomije onih koji uče (Kop \& Hill, 2008). Otuda se u literaturi (Sahin, 2012) ističe kako je od esencijalnog značaja pronalaženje balansa između potreba onih koji uče i institucionalnih potreba.

U okviru pregleda istraživanja o konektivizmu, Dauns (Downes, 2019) kritike upućene konektivizmu grupiše u okviru dva pitanja: (1) 
delovanje onih koji uče, odnosno, u okviru pitanja da li će oni koji uče biti u stanju da samousmereno uče i da se samostalno motivišu na učenje. Tu se ukazuje na to da nisu svi učenici sposobni da autonomno usmeravaju svoje učenje i ovladaju kritičkom pismenošću. Takođe, ukazuje se da je jedan deo učenika odvojen od vlastitih onlajn iskustava i da je demotivisan (Mackness \& Bell, 2015, prema: Downes, 2019), te da novi trend virtuelnog obrazovanja ugrožava čoveka na polju njegovih egzistencijalnih problema i socijalnih veza (Pando, 2018, prema: Downes, 2019), pa se otvara dilema da li konektivizam predstalja novi biheviorizam i (2) konceptualni jaz, odnosno, u okviru pitanja u kojoj se meri u konektivističkom okruženju učenja konceptualno znanje postiže kao ishod. Paradoks učenja koji navode autori (Clarà \& Barberà, 2013, prema: Downes, 2019) jeste kako prepoznati obrazac ako se već ne zna da određena konfiguracija veza predstavlja obrazac?

Ipak, čini se da najveći izazov predstavlja dilema da li se konektivizam može percipirati kao „teorija učenja“ s obzirom na to da su generalno teorije učenja komplementarne, dok $\mathrm{u}$ konektivizmu nema prostora za proširenje postojećih principa s drugim teorijama (Verhagen, 2006, prema: Chetty, 2013). U tom se okviru smatra da je konektivizam pre skup pedagoških veština, a ne teorija učenja. Tvrdi se i da je učenje prema konektivizmu radije „proces“ nego „krajnji proizvod“ (Merriam, Caffarela \& Baumghatner, 2006, prema: Chetty, 2013). Ponekad se i o konektivizmu govori kao o pedagoškom pristupu koji učenicima pruža mogućnost međusobnog povezivanja putem društvenih mreža (Giesbrecht, 2007, prema: Sahin, 2012). Ovde je reč o uočavanju ograničenja biheviorizma, kognitivizma i konstruktivizma kao teorija učenja u okviru neformalnog i 
informalnog konteksta učenja, posebno u periodu tehnološki zasnovane ere; mesto konektivizma u procesu učenja nalazi se upravo van okruženja formalnog obrazovanja. Konektivizam može da se pozicionira i kao razvoj konstruktivizma koji, u periodu upotrebe tehnologije u obrazovanju, funkcioniše kao filozofija obrazovanja (Sahin, 2012).

Izazov za konektivizam odnosi se i na činjenicu da se - koliko god danas živimo u umreženom društvu - može govoriti o postojanju digitalnog jaza. Reč je o podeli između pojedinaca koji imaju pristupa informacionim i komunikacionim tehnologijama i onih koji ga nemaju, bez obzira na to da li je u pitanju nedostatak digitalnog iskustva, neposedovanje računara ili mrežnog pristupa ili nedostatak digitalnih veština (Jandrić i Boras, 2013; Sahin, 2012). Ponekad se naglašava i pitanje kontrole. Unutar konektivističkog pristupa kontrola je smanjena i nastavnik je postavljen na periferiji procesa učenja (Bell, 2010, prema: Chetty, 2013). Konektivizam se ponekad pozicionira i na nivou kurikuluma, a ne nove teorija učenja (Bell, 2011). Takođe, ističe se da su neki od glavnih izazova s kojima se suočava konektivizam sledeći: (1) kognitivno preopterećenje koje proizlazi iz viška informacija, što ugrožava sposobnost učenika da ih uspešno zadrži i procesuira, (2) neuspeh nastavnika da neguju metakognitivne sposobnosti i (3) neuspeh povezivanja u mrežu (Downes, 2013, prema: Chetty, 2013).

U literaturi se, takođe, naglašava da jedan od najvećih rizika konektivizma predstavlja činjenica da je veština kretanja na mreži prisutnija kod kategorije tehnološki obrazovanih odraslih ljudi $\mathrm{s}$ razvijenim metakognitivnim sposobnostima i znanjem u određenom polju, dok je mnogo ređe prisutna unutar svih ostalih kategorija (Calvani, 2008). Posledično, nedovoljno osmišljena primena konektivizma u obrazovnim 
institucijama može da navede pomisao da je omogućavanje mrežnog pristupa učenicima dovoljno za učenje, čime se učvršćuje široko rasprostranjeno uverenje prema kojem je za unapređivanje učenja potrebno primenjivati što više tehnologije. Otuda, kada se pretpostavlja da deca spontano uče da deluju u mreži, treba imati na umu da se to delovanje najčešće tiče samo najnižih nivoa tehničke funkcionalnosti. Za osmišljeno kretanja na mreži, za uočavanje razlika između bitnih i nebitnih informacija i za upravljanje tim informacijama, potrebne su metakognitivne sposobnosti, konceptualni horizont koji mladi ljudi uobičajeno još ne poseduju, posebno ako su isključivo odrastali u digitalnoj kulturi; njihove aktivnosti na mreži na kraju ostaju uglavnom neorganizovane i površne (Calvani, 2008).

Razvijanje sposobnosti da se osmišljeno koristi mreža jeste zadatak koji obrazovne institucije moraju namerno i postepeno da postignu putem modaliteta i oblika koji se traže delimično i van tehnološke dimenzije. Takođe, potrebno je voditi računa i o tome da mnogi pojedinci ostaju privrženi suštinski transmisivnom tipu uverenja o učenju, preferirajući više izvesnosti (Calvani, 2008). Pojedini autori (Kerr, 2007, prema: Kop \& Hill, 2008) sugerišu da nijedna teorija, uključujući konektivizam, ne objašnjava dovoljno mišljenje višeg reda kao mehanizam koji obuhvata mozak, percepciju i životno okruženje. Shvatanje da znanje nije učenje ili obrazovanje, izaziva konektivizam da objasni unutrašnje procese koji vode ka dubokom razmišljanju i razumevanju. Još jedan izazov podrazumeva zavisnost od tehnologije čija primena može da rezultira izolacijom od društvenog života. Pojedinci mogu da preferiraju virtuelnu stvarnost kad god imaju problema u društvu i životu. 


\section{ZAKLJUČNA RAZMATRANJA}

Konektivizam, prateći tehnološki napredak, predstavlja danas značajno teorijsko i istraživačko pitanje koje se aktuelizuje najvećim delom u okviru proučavanja elektronskog učenja, kao pedagoška osnova koja se nadovezuje na konstruktivističke teorije učenja. Međutim, istovremeno se ukazuju i na manjkavosti konektivizma, koje je potrebno imati u vidu ukoliko se o konektivizmu govori kao o novoj teoriji učenja.

$\mathrm{Na}$ osnovu analize literature zaključuje se da u praksi konektivizam predstavlja značajan pristup učenju, dok se istovremeno ističu i njegovi mnogi nedostaci. Ipak, s obzirom na pažnju koju autori posvećuju konektivizmu, uključujući kako pristalice tako i kritičare, neophodno je poznavanje njegovih osnova bilo da se govori o pristupu konektivizmu kao potencijalnoj teoriji učenja za digitalno doba ili pedagoškom pristupu. Kada je reč o povezanosti konektivizma s Iličevim idejama o mrežama učenja kao delu teorija deškolovanja, konektivizam se može odrediti i kao pristup u okviru kojeg se u oblasti obrazovanja sve više zaobilaze insitucije formalnog obrazovanja, a sve veći značaj pridaje pojedincu. Značajnu razliku u odnosu na Iličeve mreže učenja predstavlja činjenica da konektivizam uključuje onlajn mreže, odnosno učenje posredstvom novih tehnologija. U celini posmatrano, iako konektivizam sadrži mnoge konceptualne nejasnoće, značaj njegovog proučavanja zasniva se na aktivnostima društvenih mreža i aktuelnosti onlajn obrazovanja, kao i inicijativa u okviru kojih se institucijama pridaje sve manji značaj u odnosu na pojedince. 


\title{
THEORY OF CONNECTIVISM IN EDUCATION
}

\begin{abstract}
The increasing advancement of technology in the educational process has resulted in the actualization of the phrase about technology-oriented pedagogy within learning for the digital age. In order to link connectivism with pedagogy, the aim of the paper is to set an analytical approach to connectivism, which is defined as a theory of learning for the digital age within online learning. The aim is concretized on the following tasks: presenting basic assumptions of connectivism as a potential new theory of learning, and connecting it to the idea of learning of Ivan Illich within the theory of deschooling, linking connectivism with previous theories of learning (behaviorism, cognitivism and constructivism), as well as pointing out criticisms of connectivism. Based on the presented literature, conclusions are made about the possibility of application and actualization of connectivism in the future.

Key words: connectivism, constructivism, online learning, theory of deschooling
\end{abstract}




\section{REFERENCE}

Bali, M. (2014). MOOC pedagogy: Gleaning good practice from existing MOOCs. Journal of Online Learning and Teaching, 10(1), 44-56.

Barnett, J., McPherson, V., \& Sandieson, R. M. (2013). Connected teaching and learning: The uses and implications of connectivism in an online class. Australasian Journal of Educational Technology, 29(5), 685698.

Bell, F. (2011). Connectivism: Its place in theory-informed research and innovation in technology-enabled learning. International Review of Research in Open and Distance Learning, 12(3), 98-118.

Calvani, A. (2008). Connectivism: New paradigm or fascinating pot-pourri? Journal of e-learning and Knowledge Society, 4(1), 247-252.

Chetty, D. (2013). Connectivism: Probing prospects for a technologycentered pedagogical transition in religious studies. Alternation, 10(Special Edition), 172-199. Retrieved 3.7.2021. from http://alternation.ukzn.ac.za/Files/docs/20.7/09\%20Che.pdf

Downes, S. (2019). Recent work in connectivism. European Journal of Open, Distance and e-Learning, 22(2), 113-132.

Freire, P. (2002). Pedagogija obespravljenih. Zagreb: Odraz - Održivi razvoj zajednice

Ilič. I (1980). Dole škole. Beograd: Beogradski izdavačko-grafički zavod. Jandrić, P. i Boras, D. (2013). Kritičko E-obrazovanje: borba za moć $i$ značenje u umrě̌enom društvu. Beograd: Eduka.

Klajn, I. i Šipka, M. (2012). Veliki rečnik stranih reči i izraza. Novi Sad: Prometej.

Kop, R. (2011). The challenges to connectivist learning on open online networks: Learning experiences during a massive open online course. International Review of Research in Open and Distance Learning, 12(3), 19-38.

Kop, R., \& Hill, A. (2008). Connectivism: Learning theory of the future or vestige of the past? International Review of Research in Open and Distance Learning, 9(3),1-13. 
Pavlović D. i Petrović, D. (2019). Teorija konektivizam i učenje stranih jezika.U D. Pralica i N. Šinković (Ur.), Digitalne medijske tehnologije i društveno-obrazovne promene, 8 (305-317). Novi Sad: Filozofski fakultet.

Şahin, M. (2012). Pros and cons of connectivism as a learning theory. International Journal of Physical and Social Sciences 2(4), 437454.

Siemens, G. (2005). Connectivism: A learning theory for the digital age. Retrieved 23.04.2021 fromhttps://jotamac.typepad.com/jotamacs_ weblog/files/Connectivism.pdf

Siemens, G. (2012). Orientation: Sensemaking and wayfinding in complex distributed online information environments (Unpublished Doctoral dissertation). UK: University of the Highlands and Islands. Retrieved 3.7.2021. from https://pureadmin.uhi.ac.uk/ws/portalfiles/ portal/3077978/George_Siemens_thesis.pdf

Utecht, J., \& Keller, D. (2019). Becoming relevant again: Applying connectivism learning theory to today's classrooms. Critical Questions in Education, 10(2), 107-119.

Votson, R. (2016). Budući umovi, kako digitalno doba menja naš um. Beograd: Plato. 